\title{
Variation of growth and functional traits of invasive knotweeds (Fallopia spp.) in Belgium
}

\author{
Basile Herpigny $\cdot$ Nicolas Dassonville $\cdot$ \\ Philippe Ghysels • Grégory Mahy • Pierre Meerts
}

Received: 24 March 2011/Accepted: 4 October 2011

(C) Springer Science+Business Media B.V. 2011

\begin{abstract}
Three invasive Fallopia taxa are present in Belgium: F. japonica (FJ), F. sachalinensis (FS) and their hybrid $F . \times$ bohemica $(\mathrm{FB})$. FS is the least invasive of the three taxa. In this study, we compared the taxa, in sites where they co-occur, for differences in functional traits that might influence their competitive ability and invasiveness - shoot height and ramification, leaf size, specific leaf area (SLA) and foliar nitrogen $(\mathrm{N})$ concentration. The three taxa exhibited similar growth kinetics and similar SLA. However, FS differed in its architecture and allocation of leaf area, having less ramified shoots and a steeper gradient of decreasing leaf size along the main shoot. Also, FS had greater foliar $\mathrm{N}$ and less efficient $\mathrm{N}$ resorption from senescing leaves. These traits values may result in lower competitive ability of FS for light and nitrogen. For the same traits, FB was generally intermediate between FS and FJ, but often closer to the latter. FB was more variable than FS and FJ, possibly due to larger genetic variation. SLA and ramification varied greatly amongst sites for all taxa, due in part to
\end{abstract}

B. Herpigny $(\square) \cdot$ N. Dassonville $\cdot$ P. Ghysels .

P. Meerts

Laboratoire d'Ecologie Végétale et Biogéochimie,

Université Libre de Bruxelles, AV FD Roosevelt 50, CP

244, 1050 Brussels, Belgium

e-mail: bherpign@ulb.ac.be

G. Mahy

Unité Biodiversité et Paysage, Gembloux AgroBioTech,

Université de Liège, Liège, Belgium plastic response to contrasting light regimes. Variation in functional traits values may in part explain the variation in invasiveness amongst the members of the Fallopia complex in Belgium.

Keywords Biological invasions - Functional traits · Fallopia $\cdot$ Nitrogen $\cdot$ Growth $\cdot$ SLA

\section{Introduction}

Biological invasions happen when a species with high invasiveness is introduced in an ecosystem with a high invasibility (Hobbs and Humphries 1995; Lonsdale 1999). Invasiveness is determined by reproductive output and dispersion capacity, which determine propagule pressure, and by the ability to establish, survive and compete with the resident community (Rejmanek and Richardson 1996; Rejmanek 2000; Theoharides and Dukes 2007). In the high fertility conditions where most invasive species thrive best (Dukes and Mooney 1999, Alpert et al. 2000), competitive ability is influenced by a number of functional traits, conferring fast resource capture and use (Grime 2001).

Although success of invasive plants may depend on the context of the invasion (Theoharides and Dukes 2007) and on the scale of study (Speek et al. 2011), several recent studies have shown that invasive species generally display higher values of traits 
involved in fast resource capture and use including specific leaf area (SLA), relative growth rate and foliar nutrient concentrations compared to their native counterparts (Smith and Knapp 2001; Lake and Leishman 2004; Hamilton et al. 2005; Grotkopp and Rejmanek 2007; Leishman et al. 2007; Pyšek and Richardson 2007; van Kleunen et al. 2010). Variation in invasiveness between closely related exotic species and amongst genotypes within species has also been related to variation in functional traits involved in resource capture and use (Thiébaud et al. 1996; Grotkopp et al. 2002; Gerlach and Rice 2003; Barney et al. 2005).

Hybridization plays a central role in the invasive success of a number of alien taxa (Abbott 1992; Ellstrand and Schierenbeck 2000; Lee 2002). Whilst an exotic species might not be invasive, hybridization with a native or another exotic species might produce hybrid genotypes more able to spread in new environments and more invasive (Vila et al. 2000). Such new hybrid taxa have increased genetic diversity compared to their parents, either because they combine their genetic pools, or because polyploidy restored fertility and allowed sexual reproduction which, in turn, increased genetic diversity (Soltis and Soltis 2000). This is the case in the genus Spartina (Ainouche et al. 2003; Salmon et al. 2005) or Senecio (Abbott and Lowe 2004).

Japanese knotweed (Fallopia japonica, FJ) was introduced from Eastern Asia to Europe in the course of the nineteenth century (Beerling et al. 1994; Alberternst and Böhmer 2006). All European Japanese knotweed plants are octoploid $(2 n=88)$, genetically uniform and male sterile (Mandak et al. 2004). However, due to a particularly efficient vegetative reproduction (Bimova et al. 2003; Pyšek et al. 2003), Japanese knotweed is one of the most common invasive plants in Europe.

Giant knotweed (Fallopia sachalinensis) was also introduced in Europe in the course of the nineteenth century. It is mostly tetraploid $(4 n=44)$ (Bailey and Stace 1992) and comprises male fertile and male sterile individuals in Europe. Interestingly, even though FJ and F. sachalinensis (FS) share the same growth form (large geophytic shrubs with annual shoots), the latter is much less invasive than the former (Mandak et al. 2004). In particular, FS is still very rare in Belgium (Van Landuyt et al. 2006; Vanderhoeven et al. 2006; Verloove 2006).
FS can sire FJ. The resulting hybrid, Bohemian knotweed (Fallopia $\times$ bohemica, FB) appears to be spreading quite rapidly in Central and Western Europe and might actually be more invasive than both parents (Mandak et al. 2004) though this was not confirmed in Belgium (Tiébré et al. 2008). FB has rapidly become more widespread than FS in Belgium (Meerts and Tiébré 2007; Tiébré et al. 2007a).

Bohemian knotweeds can be male fertile, and can cross with other members of the complex. Because of the numerous crosses and backcrosses, lots of hybrids are formed with different levels of ploidy (including hexaploid, octoploid and aneuploid hybrids) (Hollingsworth and Bailey 2000; Mandak et al. 2003; Tiébré et al. 2007b; Bailey et al. 2009; Krebs et al. 2009). Accordingly, FB has more genetic diversity than both parent species in Belgium (Tiébré et al. 2007a). Moreover and surprisingly most Bohemian knotweeds have their own genetic pool, different from both parental gene pools (Tiébré et al. 2007b). FB shows genotypic variation in invasiveness (Schnitzler and Bailey 2008), which has been ascribed to variation in the efficiency of vegetative regeneration from rhizome fragments (Mandak et al. 2004). It also has a broader ecological niche, due both to genetic variation and plasticity (Walls 2010).

Difference in invasiveness amongst members of the complex might be due in part to differences in functional traits, which are traits influencing fitness (Violle et al. 2007). In particular, very high stem elongation rate and the ability to quickly develop a dense canopy may impart a high competitive ability for light (Marigo and Pautou 1998). High nitrogen use efficiency may also be a key attribute of the complex (Dassonville et al. 2011; Aguilera et al. 2010).

We examined variation in functional traits that might be correlated with competitive ability and invasive success amongst members of the complex. In particular, we focused on whole plant traits implicated in light capture and use (canopy architecture), and on foliar traits that are known to be correlated with growth rate, nutrient use and competitive ability (SLA, nitrogen concentration, Wright et al. 2004). The study is based upon observations in the field, in sites where two or three taxa co-occur. We used such sites as surrogates of common garden experiments, assuming that phenotypic differences between closely adjacent plants have a genetic basis. The observations have been replicated in several sites 
for 2 years, thus allowing us to compare variation amongst taxa with variation due to growth conditions (site and year).

We examined which traits are most variable amongst members of the complex. More specifically, we examined if FB was intermediate between FJ and FS or if, alternatively, it showed transgressive variation in a number of traits. We also predicted that FS has lower values of traits associated with fast growth.

\section{Materials and methods}

\section{Site selection}

We extensively prospected Central Belgium in 2007 to find sites comprising two or three taxa of the complex. Such sites proved to be rare. Taxon identification was mainly based on leaf hairiness and leaf base morphology (FJ: glabrous, leaf base truncate; FB: hairs 1-2 celled $0.6 \mathrm{~mm}$ long, leaf base slightly cordate; FS: multicellular hairs $>1 \mathrm{~mm}$ long, leaf base cordate, Tiébré et al. 2007a; Bailey et al. 2009). Five sites having well-established, closely adjacent populations of 2 or 3 taxa were selected in the region of Brussels, Belgium (Table 1). A population is here defined as 'a collection of individuals of the same species living in the same area' (Silvertown and Lovett-Doust 1993). Our materials have not been genotypified. However, due to extremely efficient vegetative reproduction in the complex, many local populations are expected to be monomorphic. This is certainly true of FJ which is represented in Europe by a single male sterile clone (Krebs et al. 2009). In all sites, the different populations were adjacent but not intermingled. Two sites had all three taxa (FJ, FS and FB). Two sites had FJ and FB. One site with only FS was selected to increase sample size for this rare taxon. The sites were mostly wastelands, the typical habitat of Japanese knotweeds in urbanised areas (Tiébré et al. 2008). However, in site Jardin Jean Massart (JJM), the three taxa have been cultivated for 10 years in a botanical garden. The site was nonetheless included in the study because it was the only one where age of the populations and environmental conditions were known to be the same. Fallopia populations were well established in all sites, although the small area of the FB population in Diegem (DIE) site suggested a more recent origin than the other populations (except those in JJM site). All measurements in different taxa in the same site have been taken from adjacent populations. Therefore, we assume that phenotypic differences, if any, may likely have a genetic basis. Two kinds of measurements were conducted, i.e. continued growth monitoring throughout growth season in 2008 and 2009, and measurements of leaf traits at the peak of biomass in 2008.

At each site, 4 soil samples were collected under each population $(0-10 \mathrm{~cm}$, litter discarded). Soil samples were dried at room temperature, sieved at $2 \mathrm{~mm}$ and crushed ( $2 \mathrm{~mm}$ for $\mathrm{pH}$ and $\mathrm{P} ; 0.2 \mathrm{~mm}$ for $\mathrm{C}$ and $\mathrm{N}$ analysis). $\mathrm{pH}$ was measured (stiff paste soil$\mathrm{H}_{2} \mathrm{O}$ ). $\mathrm{C}$ and $\mathrm{N}$ concentrations were measured using a dry combustion $\mathrm{C}-\mathrm{N}$ analyser (TruSpec analyzer $\mathrm{CN}$, Leco, USA). P was extracted using $10 \mathrm{~g}$ dry soil, $50 \mathrm{ml} \mathrm{CH}_{3} \mathrm{COONH}_{4}$ at $\mathrm{pH}$ 4.65. $\mathrm{P}$ concentration was measured using ICP-AES determination (Vista MPX, Varian, USA). Results are included in Table 1.

\section{Growth monitoring}

For each population, growth of six randomly selected healthy shoots was measured. Different shoots were typically a few meters apart, and younger shoots at the edge of the stands were discarded. Shoot height, number of leaves and internodes on the main axis, number of secondary and tertiary ramifications were measured once a month, in April, May, June and July (afterwards the growth was negligible).

The monitoring scheme was slightly changed in 2009. Ten shoots were selected in each population. Populations in DIE and Héronnière (HER) site were destroyed in the course of the year 2009 and could not be included.

\section{Leaf traits}

SLA was measured at biomass peak (July) in 2008. Leaves from the 15th and 25th node of the main axis were taken from ten randomly selected shoots in each population. They were immediately wrapped in wet absorbent paper and placed in individual sealed plastic bags. The bags were put in an icebox and brought back to the lab and their area was immediately measured. Leaf rehydration following Cornelissen et al. (2003) protocol proved impossible: due to high evapotranspiration, the big leaves of FS never recovered turgescence when cut and placed in water. Leaf area was measured using ImageJScan software on leaf 
Table 1 Site location (VER Verrewinkel, JJM Jardin Jean Massart, PI Petite Ile, DIE Diegem, HER Héronnière), presence of the different Fallopia taxa (FJ Fallopia japonica, FB F. $\times$ bohemica, FS F. sachalinensis) and characteristics of the sites

\begin{tabular}{|c|c|c|c|c|c|}
\hline Site & VER & JJM & PI & DIE & HER \\
\hline Taxa & FJ, FB, FS & FJ, FB, FS & FJ, FB & FJ, FB & FS \\
\hline Latitude & $50^{\circ} 46^{\prime} 57^{\prime \prime}$ & $50^{\circ} 48^{\prime} 47^{\prime \prime}$ & $50^{\circ} 49^{\prime} 42^{\prime \prime}$ & $50^{\circ} 53^{\prime} 46^{\prime \prime}$ & $50^{\circ} 47^{\prime} 55^{\prime \prime}$ \\
\hline Longitude & $4^{\circ} 21^{\prime} 09^{\prime \prime}$ & $4^{\circ} 26^{\prime} 20^{\prime \prime}$ & $4^{\circ} 18^{\prime} 59^{\prime \prime}$ & $4^{\circ} 26^{\prime} 00^{\prime \prime}$ & $4^{\circ} 26^{\prime} 07^{\prime \prime}$ \\
\hline $\mathrm{C}(\%)$ & $4 \pm 2.1$ & $6.9 \pm 0.32$ & $2.9 \pm 5.4$ & $2.2 \pm 1.4$ & $2.7 \pm 0.5$ \\
\hline $\mathrm{N}(\%)$ & $0.15 \pm 0.09$ & $0.17 \pm 0.03$ & $0.19 \pm 0.12$ & $0.11 \pm 0.09$ & $0.17 \pm 0.03$ \\
\hline $\mathrm{P}(\mu \mathrm{g} / \mathrm{g})$ & $36 \pm 24$ & $4 \pm 0.93$ & $24 \pm 11$ & $16 \pm 9.8$ & $11 \pm 4.3$ \\
\hline $\mathrm{pH}$ & $7.2 \pm 0.19$ & $4.9 \pm 0.28$ & $7.1 \pm 0.13$ & $7.4 \pm 0.13$ & $5.9 \pm 0.22$ \\
\hline Light & Partial shade & Open & Open & Partial shade & Understory \\
\hline Invaded area $\left(\mathrm{m}^{2}\right)$ & FJ: 400; FB: 500; FS: 200 & FJ: 1 ; FB: 1 ; FS: 1 & FJ: 250; FB: 500 & FJ: 400; FB: 50 & FS: 16 \\
\hline Perturbation history & Heavily transformed & Undisturbed & Heavily transformed & Heavily transformed & Undisturbed \\
\hline
\end{tabular}

Mean values $(n=4$ composite samples per taxa in each site) \pm standard deviations for $\mathrm{C}, \mathrm{N}, \mathrm{P}$ and $\mathrm{pH}$

photographs. The leaves were placed between a cardboard and a plastic sheet to ensure they were laid down flat before the photographs were taken. They were then oven dried at $40^{\circ} \mathrm{C}$ during $72 \mathrm{~h}$ before measuring dry weight.

The leaves used for the SLA measurements were crushed after drying and their nitrogen and carbon concentration was measured using a dry combustion C-N analyser (TruSpec Analyzer CN, Leco, USA).

In October 2008 in site Verrewinkel (VER), senescing leaves were harvested from the 15th and 25th internode of main axis of six randomly selected shoots from each taxon. Their $\mathrm{N}$ concentration was measured. The efficiency of $\mathrm{N}$ resorption was calculated as the ([N $N_{\text {green }}$ leaves $\left.]-\left[N_{\text {senescing leaves }}\right]\right) /$ $\left[N_{\text {green leaves }}\right]$ (Killingbeck 1996).

Statistical analysis

Analyses were performed with Statistica 71 software (StatSoft Inc 2005). To obtain an overview of the differences between sites and taxa, a PCA (principal component analysis) was performed including nine variables (five growth traits: height, number of leaves and internodes on primary axis, number of secondary and tertiary ramifications, in 2008, and four leaf traits: SLA and area of leaves from the 15th and 25th internode of the main axis) in all of the 11 populations (sites VER, JJM, DIE, HER and Petite Ile (PI)).

ANOVAs were performed on growth traits (height, number of leaves and internodes on primary axis, number of secondary and tertiary ramifications). Oneway ANOVAs with taxon as main factor were performed for each site where several taxa are found, once each year at biomass peak. Data was transformed when necessary to restore homoscedasticity. The following variables were log-transformed: number of tertiary ramifications (site JJM in 2009), number of leaves and internodes (site PI in 2008), and number of tertiary ramifications (site PI in 2009). The following variables were square root-transformed: number of internodes and secondary ramifications (site JJM in 2009). No transformation restoring homoscedasticity was found for height at site DIE.

Three-way ANOVAs (taxon, site and year) were performed for each trait separately for sites with three taxa (JJM, VER) and for sites with two taxa (FJ and FB: JJM, VER and PI). DIE site was not included because the plants were destroyed in 2009. The following variables were log-transformed to restore homoscedasticity: number of tertiary ramifications for the three taxa ANOVA, number of secondary and tertiary ramifications for the two taxa ANOVA. The following variables were arctg transformed: height for the three taxa ANOVA. No transformation restoring homoscedasticity was found for number of leaves for the two taxa ANOVA. Non-parametric tests were performed, with the same results as the ANOVA. Results of the ANOVA for number of leaves were thus conserved in the table.

Repeated measures two-way ANOVA was performed for height and number of secondary 
ramifications for sites with three taxa (VER, JJM) in 2008 and in 2009. Four repetitions were included, one for each month between April and July.

Two-way ANOVAs (taxon, site) were conducted for SLA and leaf area of the 15th and 25th internodes (hereafter SLA 15, SLA 25, A 15 and A 25, respectively) and nitrogen concentration, separately for three- and two-taxa sites (cf supra). The following variables were log-transformed to restore homoscedasticity: A 15 and A 25 for both ANOVAs, SLA 15 for the two taxa ANOVA. SLA 25 was $\operatorname{arctg}$ transformed for the two taxa ANOVA.

A one-way ANOVA (taxon) was conducted on the efficiency of $\mathrm{N}$ resorption from leaves at VER site in 2008 ( $n=12$ leaves per taxon).

\section{Results}

PCA

Variables and cases factor coordinates are shown in Fig. 1. PC1 accounts for $46 \%$ of total variance and is correlated mostly with number of leaves $(81 \%)$, and number of secondary (98\%) and tertiary (84\%) ramifications (positive correlation) and individual leaf area (67\%) (negative correlation). PC2 accounts for $29 \%$ of total variance and is correlated positively with shoot height (88\%) and negatively with SLA (70\%). Sites tend to form distinct groups, irrespective of taxon, being mostly separated along PC1, with JJM and PI at one end of PC1 and VER at the opposite end.

In both sites with three taxa (JJM and VER), the pattern of differences amongst taxa was similar, with FJ shifted towards positive values of $\mathrm{PC} 1$ and negative values of PC2 and FS shifted towards negative values of $\mathrm{PC} 1$ and positive values of $\mathrm{PC} 2$. FB is intermediate between FJ and FS in both sites, but closer to FJ than to FS. FB in site DIE does not follow the same pattern, being shifted towards negative values of PC2, due to unusually high SLA (see 'Leaf traits' section).

Growth monitoring

Growth pattern was similar for all three taxa in both sites where they co-occur, with the fastest increase in the first 2 months (Fig. 2), followed by a plateau reached in June (no significant difference between June and July in the Tukey HSD tests performed after

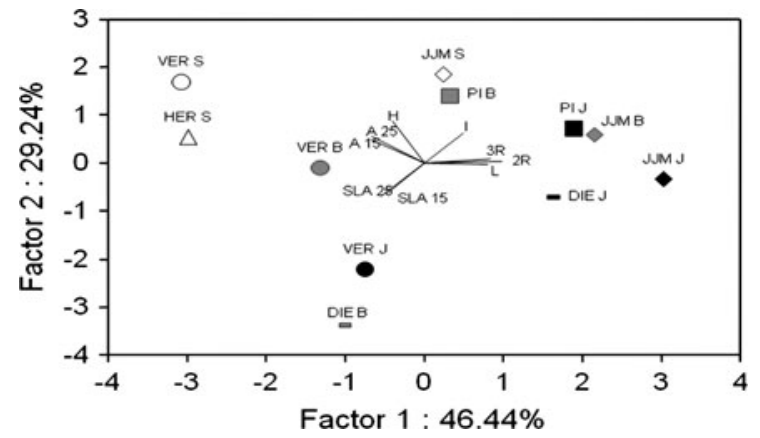

Fig. 1 PCA of growth and leaf traits in 2008. Factor coordinates of variables (vectors) and cases. FJ populations are in black, FB in grey and FS in white. Symbol indicates site (filled circles VER, filled squares PI, filled triangles HER, filled diamonds JJM, dashes DIE). Case tags indicate the site and the taxon; variable tags indicate the trait (height $(H)$, number of leaves $(L)$ and internodes $(I)$ on primary axis, number of secondary $(2 R)$ and tertiary ramifications $(3 R)$, SLA and area $(A)$ of the 15th and 25th leaf of the main axis)

the repeated measures ANOVA). In 2008 but not in 2009, the repeated measures ANOVA on height trait also shows a significant taxon effect $(F$ value $=4.53$, df $=2, P=0.02)$ and a significant time*taxon interaction $(F$ value $=8.54, \mathrm{df}=6, P<0.001)$ with a difference in growth duration: $F J$ height reached the plateau ca. 1 month earlier than FS, and FB was intermediate. Height at biomass peak varied between 246 and $310 \mathrm{~cm}$ for FJ, between 225 and $334 \mathrm{~cm}$ for FB and between 306 and $353 \mathrm{~cm}$ for FS. A significant taxon effect was found only in sites VER and JJM (2008) (one-way ANOVAs: Table 2) with FS being higher than FJ and the hybrid being intermediate (significant Tukey HSD test). In DIE site, ANOVA could not be performed due to heteroscedasticity. Instead Mann-Whitney $U$ test was performed but no significant differences were found. In the three-way ANOVA (Table 3), there were significant taxon and year effects but also a significant taxon*year interaction, showing that differences in height amongst taxa disappeared in 2009, in line with Fig. 2b.

Very few significant effects were found for number of leaves and number of internodes in both ANOVAs (one-way ANOVAs: Table 2, three-way ANOVAs: Table 3). Only the site effect was highly significant in the three-way ANOVA. Taxon effect was never significant.

The number of secondary ramifications was systematically smaller for FS (between 6 and 25) compared to the other taxa (between 17 and 39 for 
Fig. 2 Time variation of shoot height (mean $\pm \mathrm{SE}$; in 2008: a, in 2009: b) and number of secondary ramifications (in 2008: c, in 2009: d) of the three Fallopia taxa in sites where they co-occur. $n=6$ Shoots per taxon in each site in 2008 and $n=10$ in 2009. Black symbols: FJ, grey: FB, white: FS. Symbol shapes indicate the site (filled circles VER, filled diamonds JJM). Time axis represents the number of days since the beginning of the measurements (17th of March 2008 or 2009 , respectively)
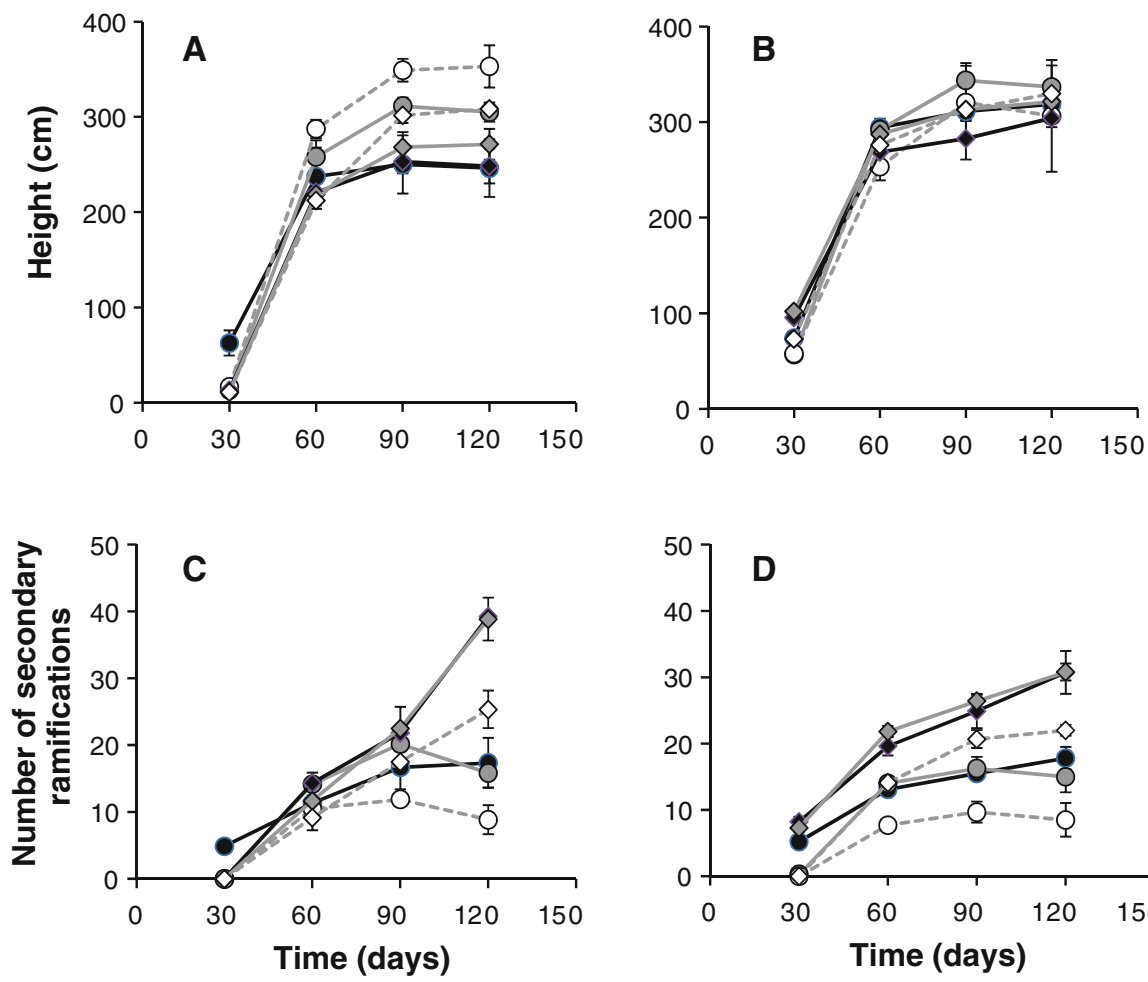

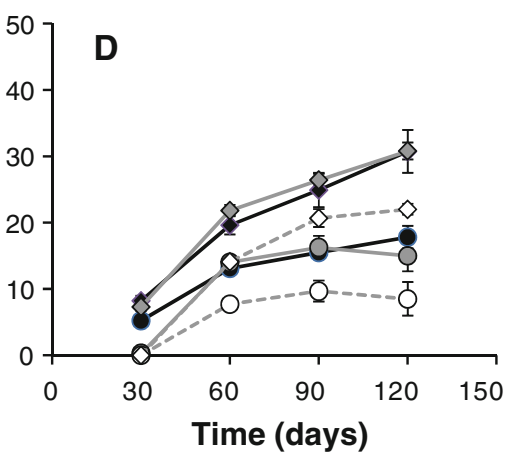

Table $2 F$ values of the one-way ANOVAs (taxon effect) for growth traits at biomass peak (height $(H)$, number of leaves $(L)$ and internodes $(I)$ on primary axis, number of secondary $(2 R)$ and tertiary ramifications $(3 R))$

\begin{tabular}{lllllllllc}
\hline Site & Year & Taxon & df & Error df & $H$ & $L$ & $I$ & $2 R$ & $3 R$ \\
\hline VER & 2008 & FJ FB FS & 2 & 15 & $5.67^{*}$ & 0.45 & 0.24 & 2.63 & 1.72 \\
VER & 2009 & FJ FB FS & 2 & 13 & 0.25 & 1.09 & 2.05 & 3.40 & 2.71 \\
JJM & 2008 & FJ FB FS & 2 & 13 & $4.54^{*}$ & 1.53 & 2.55 & $4.04^{*}$ & 1.06 \\
JJM & 2009 & FJ FB FS & 2 & 20 & 3.05 & 1.28 & 1.55 & $4.47^{*}$ & 0.59 \\
PI & 2008 & FJ FB & 1 & 8 & 0.69 & 2.03 & 0.18 & 1.15 & 1.20 \\
PI & 2009 & FJ FB & 1 & 11 & 0.77 & 2.94 & 0.03 & $14.77^{*}$ & $14.69^{* *}$ \\
DIE & 2008 & FJ FB & 1 & 10 & - & 0.66 & 0.00 & 2.91 & 1.55 \\
\hline
\end{tabular}

$N=6$ ramets per taxa in each site in 2008 and 10 ramets per taxa in each site in 2009

Significance level: * $P<0.05 ; * * P<0.01$

FJ and between 15 and 37 for FB) at all sites (Fig. 2). FJ and FB were most similar for this trait. There were large differences amongst sites however (significant site effect in the three-way ANOVA, Table 3), with all taxa being less ramified in site VER compared to the other two sites. In the one-way ANOVAs (Table 2), a significant taxon effect was found only in site JJM (both years) and PI (2009) for the number of secondary ramifications and in site PI (2009) for the number of tertiary ramifications. In JJM, FS had significantly fewer ramifications than the two other taxa and in PI, the hybrid had significantly less ramifications than FJ. In the three-way ANOVA (Table 3), the taxon effect was significant for secondary and tertiary ramifications. The only significant interaction was the site*year one. In the repeated measures ANOVA, time*taxon interaction was significant $(F$ value $=$ 50.41, df $=6, P=0.04$ ) only in 2008 with FS producing ramifications at a slower rate than the other taxa. Time* site interaction was significant in 2008 
Table $3 F$ values of the three-way ANOVAs (taxon, site and time effect) for growth traits at biomass peak (height $(H)$, number of leaves on primary axis $(L)$, number of internodes $(I)$, number of secondary $(2 R)$ and tertiary ramifications $(3 R)$ )

\begin{tabular}{|c|c|c|c|c|c|c|c|}
\hline Category of sites & Effect & df & $H$ & $L$ & $I$ & $2 R$ & $3 R$ \\
\hline \multirow[t]{8}{*}{ Three taxa sites (VER, JJM: FJ, FB, FS) } & Taxon & 2 & $3 *$ & 1.19 & 0.10 & $14.92 * * *$ & $9.17 * * *$ \\
\hline & Site & 1 & 0 & $83.96 * * *$ & $27.35^{* * *}$ & $112.95 * * *$ & $104.87 * * *$ \\
\hline & Year & 1 & $4^{*}$ & 3.66 & 3.15 & $4.48 *$ & 0.00 \\
\hline & Taxon $*$ site & 2 & 1 & 1.98 & 1.73 & 0.64 & 2.63 \\
\hline & Taxon $*$ year & 2 & $4^{*}$ & 0.05 & $4.78^{*}$ & 0.25 & 0.33 \\
\hline & Site * year & 1 & 1 & 0.63 & 0.02 & $3.89 *$ & 0.00 \\
\hline & Taxon $*$ site $*$ year & 2 & 1 & 0.16 & 0.53 & 0.28 & 0.59 \\
\hline & Error & 61 & & & & & \\
\hline \multirow[t]{8}{*}{ Two taxa sites (VER, JJM, PI: FJ and FB) } & Taxon & 1 & $7.05^{*}$ & 0.23 & 0.20 & 2.58 & $8.95 * *$ \\
\hline & Site & 2 & 0.90 & $22.57 * * *$ & $9.07 * * *$ & $34.21 * * *$ & $31.01 * * *$ \\
\hline & Year & 1 & 3.53 & 3.65 & $5.62 *$ & $5.16^{*}$ & 2.82 \\
\hline & Taxon $*$ site & 2 & 0.44 & 1.79 & 0.25 & 1.67 & 1.25 \\
\hline & Taxon $*$ year & 1 & 0.96 & 1.75 & 0.10 & 1.23 & 2.83 \\
\hline & Site * year & 2 & $12.17 * * *$ & 0.50 & $3.93 *$ & 2.29 & 1.73 \\
\hline & Taxon $*$ site $*$ year & 2 & 0.32 & 1.62 & 0.51 & 0.33 & 1.44 \\
\hline & Error & 61 & & & & & \\
\hline
\end{tabular}

$n=6$ Ramets per taxa in each site in 2008 and $n=10$ in 2009

Significance level: * $P<0.05$; ** $P<0.01$; *** $P<0.001$

$(F$ value $=22.84$, df $=3, P<0.001)$ and 2009

Leaf nitrogen concentration ranged from 1.65 to $(F$ value $=22.87, \mathrm{df}=3, P<0.001)$, with plants in JJM growing ramifications faster than in VER.

\section{Leaf traits}

SLA ranged from ca. 8 to $27 \mathrm{~m}^{2} / \mathrm{kg}$. Much of that variation was due to differences between leaves within plants, with the 25th leaf generally having lower SLA compared to 15th leaf (Fig. 3a). No clear pattern of difference was found amongst members of the complex (Fig. 3a). This is due to large site or taxon*site interaction effects in two-taxa sites (Table 4). In threetaxa sites, the slightly significant taxon effect is due to lower values of FB compared to either parent. In site DIE, FB had the highest value recorded in any taxon at any site.

Leaf area ranged from ca. $70-850 \mathrm{~cm}^{2}$ (Fig. 3b). There is a clear pattern of variation amongst taxa, with FS having ca. sixfold and threefold larger leaves compared to FB and FJ (highly significant taxon effect in the two-way ANOVAs, Table 4). Lower leaves were generally larger than upper leaves, and this pattern was much more striking for FS compared to the other two taxa, with a two- to threefold drop from the 15 th and the 25 th leaf. FB was closer to FJ in this respect. $2.4 \%$ (Fig. 3c). FS had significantly higher values compared to FJ (significant taxon effect in the twoway ANOVA). Interestingly, FB was most variable, with much higher values in site VER compared to site JJM. No such variation between the two sites was observed for the other two taxa.

In site VER, FS and FB had higher $\mathrm{N}$ concentrations in summer leaves compared to FJ (cf the results of the pairwise comparison tests included in Fig. 4). $\mathrm{N}$ concentrations were lower in senescing leaves for all taxa. The ANOVA performed on efficiency of $\mathrm{N}$ resorption showed a significant taxon effect $(F$ value $=5.28, \mathrm{df}=2$, error $\mathrm{df}=33, P=0.01)$ and the Tukey HSD test showed a significant difference between FS and the two other taxa, with FS resorbing ca. $39 \%$ of nitrogen from senescing leaves, versus 58 and $55 \%$ in FJ and FB, respectively.

\section{Discussion}

There was large phenotypic variation in most of the examined functional traits. For many traits, there was a significant site effect and/or significant site*taxon interaction. This, in addition to the small sample size 

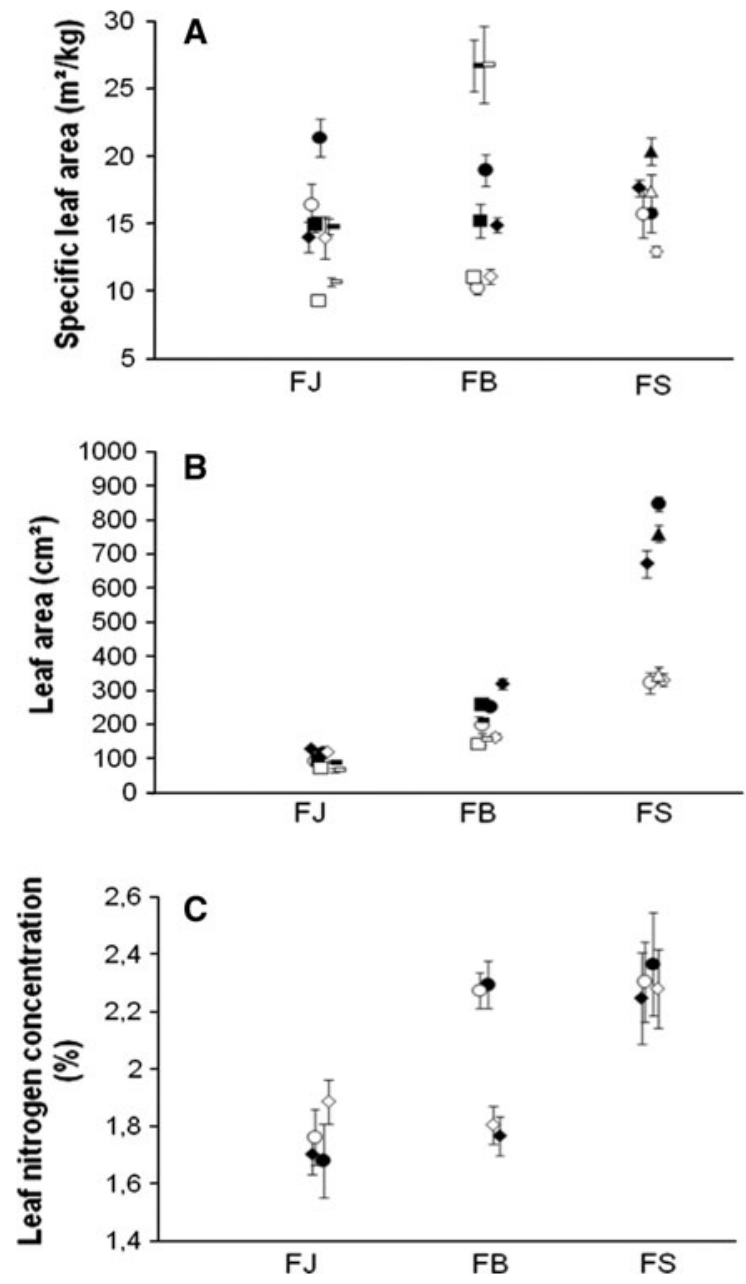

Fig. 3 Fallopia leaf traits (a SLA, b leaf area, c leaf nitrogen concentration) at biomass peak in VER (filled circles), PI (filled squares), HER (filled triangles), DIE (dashes) and JJM (filled diamonds). Mean $( \pm \mathrm{SE})$. Black shapes: 15 th leaf of primary axis, white shapes: 25 th leaf of primary axis. Leaves collected in July 2008 at sites VER and PI and in July 2009 at JJM

(five sites), calls for a cautious interpretation of the data.

FS, the least invasive taxon, showed distinct patterns for some functional traits

All three taxa have fast-growing shoots which reach 3 $\mathrm{m}$ in height in less than 2 months. The rate of shoot elongation does not appear to be different but FJ and FB tended to stop shoot elongation at an earlier date compared to FS, though this varied between the 2 years. Consistently with other studies (Hamilton et al.
2005) no clear difference in height was found between the less invasive taxon and the more invasive ones.

A more consistent difference was found for the pattern of ramification. At all sites, FS had only on average half the number of secondary ramifications compared to the other taxa, and almost no tertiary ramifications. Interestingly, two growth phases could roughly be recognized. In the first 2 months, the main axis increased rapidly in height, with little allocation to ramification. Then, the main axis stopped elongating and started ramifying. This pattern is much more obvious for FJ and FB than for FS. More ramified shoots may impart greater capacity to capture light. The high competitive ability of Asiatic knotweeds has already been ascribed to their ability to decrease light intensity under their canopy (FS: Marigo and Pautou 1998; FB: Siemens and Blossey 2007). This ability might be even more important in the more densely ramified FJ.

Leaf traits play a key role in the strategy of resource capture and use. Alien invasive plants have often been shown to display higher values of SLA (Smith and Knapp 2001; Hamilton et al. 2005; Grotkopp and Rejmanek 2007) and nitrogen concentration (Pyšek and Richardson 2007) than native species, often resulting in a faster growth rate (Grotkopp et al. 2002; Leishman et al. 2007). In this study, contrary to our expectations, FS, the taxon with the lowest invasiveness, had higher foliar nitrogen concentration and similar SLA compared to the highly invasive FJ. Interestingly, the high foliar $\mathrm{N}$ concentration in FS does not result in higher shoot growth rate, possibly pointing to lower nitrogen use efficiency.

Our results highlight the huge differences in individual leaf area amongst taxa, with a sixfold difference between FS and FJ. Interestingly, FS showed a sharp gradient of decreasing leaf size along the shoot. Taken together, the architectural attributes and leaf area point to contrasting strategies of leaf area allocation in the complex. In FS, very large leaves are quickly produced on the main shoot, apparently at the expense of further leaf production. In FJ and FB, leaf surface is more equally partitioned between the main shoot and ramifications.

Foliar nitrogen concentration varies significantly in the complex. FJ has lower $\mathrm{N}$ concentrations compared to FS ( $P=0.03$ in sites VER and JJM). As foliar N concentrations are usually correlated to photosynthetic capacity, our results possibly point to higher 
Table $4 F$ values of the two-way ANOVAs (taxon and site) for leaf traits at biomass peak (SLA of the 15th and 25th leaf of the main axis (SLA 15 and SLA 25), leaf area of the same

\begin{tabular}{|c|c|c|c|c|c|c|c|c|}
\hline Category of sites & Effect & df & SLA 15 & SLA 25 & A 15 & A 25 & N 15 & N 25 \\
\hline \multirow[t]{4}{*}{ Three taxa sites (VER, JJM) } & Taxon & 2 & 0.01 & $4.96 *$ & $753.9 * * *$ & $183.1 * * *$ & $8.57 * * *$ & $7.07 * *$ \\
\hline & Site & 1 & $6.34 *$ & 2.27 & 0.9 & $4.6^{*}$ & 3.73 & 1.55 \\
\hline & Taxon $*$ site & 2 & $4.18 *$ & 1.28 & $13.07 * * *$ & 2.3 & 2.54 & $3.40^{*}$ \\
\hline & Error & & 48 & 48 & 48 & 48 & 25 & 25 \\
\hline \multirow[t]{4}{*}{ Two taxa sites (VER, JJM, PI, DIE) } & Taxon & 1 & $9.09 * *$ & 2.5 & $817.2 * * *$ & $148.14 * * *$ & & \\
\hline & Site & 3 & $14.38 * * *$ & $14.9 * * *$ & $26.4 * * *$ & $6.89 * * *$ & & \\
\hline & Taxon * site & 3 & $11.74 * * *$ & $29.5 * * *$ & 2.3 & 0.47 & & \\
\hline & Error & & 68 & 68 & 68 & 68 & & \\
\hline
\end{tabular}

$N=10$, except nitrogen: $N=6$

Significance level: $* P<0.05$; ** $P<0.01$; *** $P<0.001$

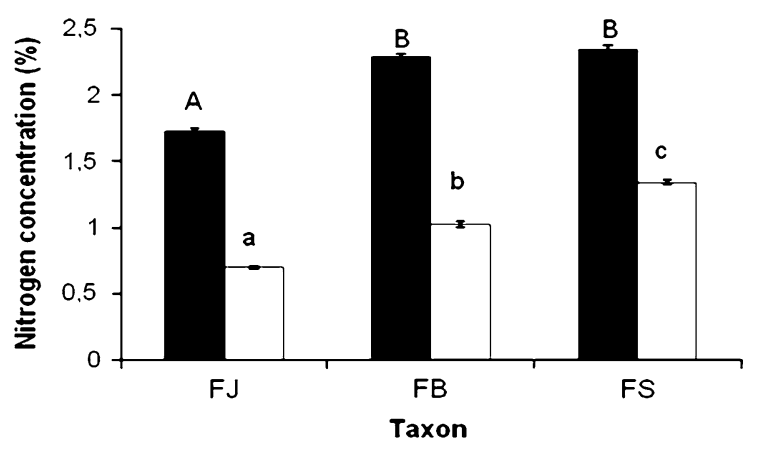

Fig. 4 Foliar nitrogen concentration in summer leaves (black) and senescing leaves (white) of the three Fallopia taxa in site VER in 2008. Mean $( \pm$ SE). $N=12$ for each taxa and each condition. Summer leaves collected at biomass peak in July and senescing leaves collected in November. Different capital letters indicate significant differences between summer leaves and different lower case letters indicate significant differences between senescing leaves $(P<0.05)$

photosynthetic capacity in FS. However, this does not result in faster increase in height. Most interestingly, nitrogen resorption from senescing leaves appears to be less efficient in FS, although this result should be taken with caution as only one site was examined. The ability to efficiently recycle $\mathrm{N}$ from senescing leaves has been put forward as one of the key attributes of invasive knotweeds enabling them to outcompete the native flora (FJ: Dassonville et al. 2011; FS: Urgenson et al. 2009). In addition, low $\mathrm{N}$ concentrations in its litter result in very slow decomposition rates and $\mathrm{N}$ immobilization (Dassonville 2008).

Together, these results may point to lower nitrogen use efficiency in FS. The litter of this taxon also leaves (A 15 and A 25), and nitrogen concentration of the same leaves ( 15 and $\mathrm{N} 25)$ ) 
variations may be different for the different members of the complex.

First, as FJ does not display genetic variation in Europe (Mandak et al. 2004; Krebs et al. 2009) any phenotypic variation must by definition have an environmental basis. Large phenotypic plasticity may be a key attribute of FJ (Richards et al. 2008). Higher values of ramification rate and lower SLA in the site JJM compared to VER are ascribable to contrasting light conditions. Indeed, in site JJM, the three taxa are represented by isolated clumps surrounded by open vegetation with shoots being exposed to an intense lateral light regime. It is worth noting that the lower nutrient status of the soil at JJM site does not seem to affect negatively plant size, suggesting that this trait is not much plastic in the complex.

$\mathrm{FB}$, in contrast to $\mathrm{FJ}$, is genetically variable both within and between populations in Belgium (Tiébré et al. 2007b; Krebs et al. 2009). Most interestingly, foliar nitrogen concentration varied broadly between sites VER and JJM for the hybrid and not for the other two taxa. This may indicate that the hybrid taxon comprises lineages with different values of key functional traits. The exceptionally high SLA of the FB in the DIE site may also be due to the presence of a different lineage of the taxon in this site compared to other sites or to the supposedly younger age of the population. As our materials have not been genotypified, the origin of the large variation observed (i.e. plasticity or genetic variation) remains unresolved.

We failed to find clear evidence for particular trait values in the hybrid which might explain its supposed higher invasiveness compared to FJ (Mandak et al. 2004). Attributes which have not been not examined here might be more important, including the ability of the hybrid to reproduce sexually, its dominance in the pollinic pool or its higher genetic diversity (Tiébré et al. 2007a; Krebs et al. 2009).

\section{Conclusions}

Japanese knotweeds are phenotypically variable for functional traits implicated in light and nitrogen capture and use and part of the variation expressed in the field is certainly of genetic origin. Our results suggest that these traits may in part explain differences in invasiveness amongst members of the complex. FS has a particular combination of traits that may result in a lower competitive ability for light and nitrogen, thus explaining lower invasiveness. Future study should test if our results hold true across the whole introduction range. However, differences in invasiveness amongst members of the complex can also be due to other attributes not examined here, including vegetative regeneration and propagule pressure. We have found no clear evidence for transgressive variation in FB. However, future study should explore genetic variation in functional traits within the hybrid taxon and compare variation in phenotypic plasticity in response to varying levels of resources across the whole complex.

Acknowledgments This study has been made possible by the funding of the 'Fonds National de la Recherche Scientifique', Belgium (FRFC 2.4605.06). B. Herpigny has a fellowship of the Fonds pour la formation à la Recherche dans l'Industrie et dans l'Agriculture.

\section{References}

Abbott RJ (1992) Plant invasions, interspecific hybridization and the evolution of new plant taxa. Trends Ecol Evol 7:401-405

Abbott RJ, Lowe AJ (2004) Origins, establishment and evolution of new polyploidy species: Senecio cambrensis and $S$. eboracensis in the British Isles. Biol J Linn Soc 82:467-474

Aguilera AG, Alpert P, Dukes JS, Harrington R (2010) Impacts of the invasive plant Fallopia japonica (Houtt.) Ronse Decraene on plant communities and ecosystem processes. Biol Invasion 12:1243-1252

Ainouche ML, Baumel A, Salmon A, Yannic G (2003) Hybridization, polyploidy and speciation in Spartina (Poaceae). New Phytol 161:165-172

Alberternst B, Böhmer HJ (2006) NOBANIS-Invasive Alien Species Fact Sheet-Fallopia japonica-from: online database of the North European and Baltic Network on Invasive Alien Species-NOBANIS. www.nobanis.org. Accessed 22 Aug 2007

Alpert P, Bone E, Holzapfel C (2000) Invasiveness, invasibility and the role of environmental stress in the spread of nonnative plants. Perspect Plant Ecol Evol Syst 3:52-66

Bailey JP, Stace CA (1992) Chromosome number, morphology, pairing, and DNA values of species and hybrids in the genus Fallopia (Polygonaceae). Plant Syst Evol 180:29-52

Bailey JP, Bimova K, Mandak B (2009) Asexual spread versus sexual reproduction and evolution in Japanese Knotweed s.l. sets the stage for the "Battle of the Clones". Biol Invasion 11:1189-1203

Barney JN, Di Tommaso A, Weston LA (2005) Differences in invasibility of two contrasting habitats and invasiveness of two mugwort Artemisia vulgaris populations. J Appl Ecol 42:567-576 
Beerling DJ, Bailey JP, Conolly AP (1994) Fallopia japonica (Houtt.) Ronse Decraene. J Ecol 82:959-979

Bimova K, Mandak B, Pyšek P (2003) Experimental study of vegetative regeneration in four invasive Reynoutria taxa (Polygonaceae). Plant Ecol 166:1-11

Cornelissen JHC, Lavorel S, Garnier E, Diaz S, Buchmann N, Gurvich DE, Reich PB, ter Steege H, Morgan HD, van der Heijden MGA, Pausas JG, Poorter H (2003) A handbook of protocols for standardised and easy measurement of plant functional traits worldwide. Aust J Bot 51:335-380

Dassonville N (2008) Impact des plantes exotiques envahissantes sur le fonctionnement des écosystèmes en Belgique. PhD Thesis, Université Libre de Bruxelles

Dassonville N, Guillaumaud N, Piola F, Meerts P, Poly F (2011) The niche construction by the invasive Asian knotweeds (species complex Fallopia): impact on activity, abundance and community structure of denitrifiers and nitrifiers. Biol Invasion. doi:10.1007/s10530-011-9954-5

Dukes JS, Mooney HA (1999) Does global change increase the success of biological invaders? Trends Ecol Evol 14: 135-139

Ellstrand NC, Schierenbeck KA (2000) Hybridization as a stimulus for the evolution of invasiveness in plants? Proc Natl Acad Sci USA 97:7043-7050

Gerlach JD, Rice KJ (2003) Testing life history correlates of invasiveness using congeneric plant species. Ecol Appl 13:67-179

Grime JP (2001) Plant strategies, vegetation processes and ecosystem functioning. Wiley, New York

Grotkopp E, Rejmanek M (2007) High seedling relative growth rate and specific leaf area are traits of invasive species: phylogenetically independent contrasts of woody angiosperms. Am J Bot 94:526-532

Grotkopp E, Rejmanek M, Rost TL (2002) Toward a causal explanation of plant invasiveness: seedling growth and life-history strategies of 29 pine (Pinus) species. Am Nat 159:396-419

Hamilton MA, Murray BR, Cadotte MW, Hose GC, Baker AC, Harris CJ, Licari D (2005) Life-history correlates of plant invasiveness at regional and continental scales. Ecol Lett 8:1066-1074

Hobbs RJ, Humphries SE (1995) An integrated approach to the ecology and management of plant invasions. Conserv Biol 9:761-770

Hollingsworth ML, Bailey JP (2000) Hybridisation and clonal diversity in some introduced Fallopia species (Polygonaceae). Watsonia 23:111-121

Killingbeck KT (1996) Nutrients in senesced leaves: keys to the search for potential resorption and resorption proficiency. Ecology 77:1716-1727

Krebs C, Mahy G, Diethart M, Schaffner U, Tiébré MS, Bizoux J-P (2009) Taxa distribution and RAPD markers indicate different origins and regional differentiation of hybrids in the invasive Fallopia complex in central Western Europe. Plant Biol 12:215-223

Lake JC, Leishman MR (2004) Invasion success of exotic plants in natural ecosystems: the role of disturbance, plant attributes and freedom from herbivores. Biol Conserv 117:215-226

Lee CE (2002) Evolutionary genetics of invasive species. Trends Ecol Evol 17:386-391
Leishman MR, Haslehurst T, Ares A, Baruch Z (2007) Leaf trait relationships of native and invasive plants: communityand global-scale comparisons. New Phytol 176:635-643

Lonsdale WM (1999) Patterns of plant invasions and the concept of invasibility. Ecology 80:1522-1536

Mandak B, Pyšek P, Lysak M, Suda J, Krahulcova A, Bimova K (2003) Variation in DNA-ploidy levels of Reynoutria taxa in the Czech Republic. Ann Bot 92:265-272

Mandak B, Pyšek P, Bimova K (2004) History of the invasion and distribution of Reynoutria taxa in the Czech Republic: a hybrid spreading faster than its parents. Preslia 76: $15-64$

Marigo G, Pautou G (1998) Phenology, growth and ecophysiological characteristics of Fallopia sachalinensis. J Veg Sci 9:379-386

Meerts P, Tiébré M-S (2007) Fallopia $\times$ bohemica est beaucoup plus répandu que $F$. sachalinensis dans la région de Bruxelles. Dumortiera 92:22-24

Pyšek P, Richardson DM (2007) Traits associated with invasiveness in alien plants: where do we stand? In: Nentwig W (ed) Biological invasions. Springer, New York, pp 97-125

Pyšek P, Brock JH, Bimova K, Mandak B, Jarosik V, Koukolikova I, Pergl J, Stepanek J (2003) Vegetative regeneration in invasive Reynoutria (Polygonaceae) taxa: the determinant of invasibility at the genotype level. Am J Bot 90: $1487-1495$

Rejmanek M (2000) Invasive plants: approaches and predictions. Aust Ecol 25:497-506

Rejmanek M, Richardson DM (1996) What attributes make some plants species more invasive? Ecology 77:16551661

Richards CL, Walls RL, Bailey JP, Parameswaran R, George T, Pigliucci M (2008) Plasticity in salt tolerance traits allows for invasion of novel habitat by Japanese knotweed s.l. (Fallopia japonica and F. $\times$ bohemica, Polygonaceae). Am J Bot 95(8):931-942

Salmon A, Ainouche ML, Wendel JF (2005) Genetic and epigenetic consequences of recent hybridization and polyploidy in Spartina (Poaceae). Mol Ecol 14:1163-1175

Schnitzler A, Bailey J (2008) Polymorphisme génétique et plasticité phénotypique: deux atouts pour la dispersion des renouées asiatiques? Rev Ecol 63:209-217

Siemens TJ, Blossey B (2007) An evaluation of mechanisms preventing growth and survival of two native species in invasive bohemian knotweed (Fallopia $\times$ bohemica, Polygonaceae). Am J Bot 94:776-783

Silvertown J, Lovett-Doust J (1993) Introduction to plant population biology. Blackwell Scientific Publications, Oxford

Smith MD, Knapp AK (2001) Physiological and morphological traits of exotic, invasive exotic, and native plant species in tallgrass prairie. Int J Plant Sci 162:785-792

Soltis PS, Soltis DE (2000) The role of genetic and genomic attributes in the success of polyploids. Proc Natl Acad Sci USA 97:7051-7057

Speek TAA, Lotz LAP, Ozinga WA, Tamis WLM, Schaminée JHJ, van der Putten WH (2011) Factors relating to regional and local success of exotic plant species in their new range. Divers Distrib 17:542-551

Theoharides KA, Dukes JS (2007) Plant invasion across space and time: factors affecting nonindigenous species success during four stages of invasion. New Phytol 176:256-273 
Thiébaud C, Finzi AC, Affre L, Debussche M, Escarre J (1996) Assessing why two introduced Conyza differ in their ability to invade Mediterranean old fields. Ecology 77:784-791

Tiébré MS, Bizoux J-P, Hardy OJ, Bailey JP, Mahy G (2007a) Hybridization and morphogenetic variation in the invasive alien Fallopia (Polygonaceae) complex in Belgium. Am J Bot 94:1900-1910

Tiébré MS, Vanderhoeven S, Saad L, Mahy G (2007b) Hybridization and sexual reproduction in the invasive alien Fallopia (Polygonaceae) complex in Belgium. Ann Bot 99:193-203

Tiébré MS, Saad L, Mahy G (2008) Landscape dynamics and habitat selection by the alien invasive Fallopia (Polygonaceae) in Belgium. Biodivers Conserv 17:2357-2370

Urgenson LS, Reichard SH, Halpern CB (2009) Community and ecosystem consequences of giant knotweed (Polygonum sachalinense) invasion into riparian forests of western Washington, USA. Biol Conserv 142:1536-1541

van Kleunen M, Weber E, Fischer M (2010) A meta-analysis of trait differences between invasive and non-invasive plant species. Ecol Lett 13:235-245

Van Landuyt W, Hoste I, Vanhecke L, Van den Bremt P, Vercruysse W, De Beer D (2006) Atlas van de Flora van Vlaanderen en het Brussels Gewest. Instituut Voor Natuuren Bosonderzoek, Nationale Plantentuin van België and Flo. Wer
Vanderhoeven S, Pieret N, Tiébré M-S, Dassonville N, Meerts P, Rossi E, Nijs I, Pairon M, Jacquemart AL, Vanhecke L, Hoste I, Verloove F, Mahy G (2006) Invasive plants in Belgium: patterns, processes and monitoring (INPLANBEL). Belgian Science Policy, Brussels

Verloove F (2006) Catalogue of neophytes in Belgium (1800-2005). National Botanic Garden, Belgium

Vila M, Weber E, D'Antonio CM (2000) Conservation implications of invasion by plant hybridization. Biol Invasion 2:207-217

Violle C, Navas M-L, Vile D, Kazakou E, Fortunel C, Garnier E (2007) Let the concept of trait be functional! Oikos 116:882-892

Walls RL (2010) Hybridization and plasticity contribute to divergence among coastal and wetland populations of invasive hybrid Japanese Knotweed sl (Fallopia spp). Estuar Coasts 33:902-918

Wright IJ, Reich PB, Westoby M, Ackerly DD, Baruch Z, Bongers F, Cavender-Barres J, Chapin T, Cornelissen JHC, Diemer M, Flexas J, Garnier E, Groom PK, Gulias J, Hikosaka K, Lamont BB, Lee T, Lee W, Lusk C, Midgley JJ, Navas ML, Niinemets U, Oleksyn J, Osada N, Poorter H, Poot P, Prior L, Pyankov VI, Roumet C, Thomas SC, Tjoelker MG, Veneklaas EJ, Villar R (2004) The worldwide leaf economics spectrum. Nature 428:821-827 